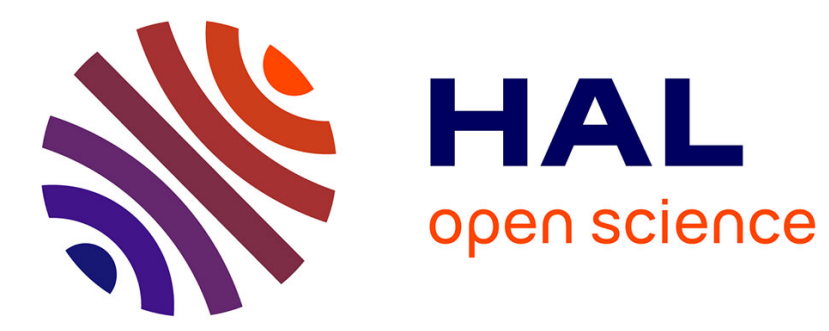

\title{
Synthesis of nano-structured high-temperature titanium aluminide by instrumented pulse electro-discharge consolidation of mechanically alloyed amorphous powder H. Kimura
}

\section{- To cite this version:}

H. Kimura. Synthesis of nano-structured high-temperature titanium aluminide by instrumented pulse electro-discharge consolidation of mechanically alloyed amorphous powder. Journal de Physique IV Proceedings, 1993, 03 (C7), pp.C7-423-C7-428. 10.1051/jp4:1993765 . jpa-00252185

HAL Id: jpa-00252185

https://hal.science/jpa-00252185

Submitted on 1 Jan 1993

HAL is a multi-disciplinary open access archive for the deposit and dissemination of scientific research documents, whether they are published or not. The documents may come from teaching and research institutions in France or abroad, or from public or private research centers.
L'archive ouverte pluridisciplinaire HAL, est destinée au dépôt et à la diffusion de documents scientifiques de niveau recherche, publiés ou non, émanant des établissements d'enseignement et de recherche français ou étrangers, des laboratoires publics ou privés. 


\title{
Synthesis of nano-structured high-temperature titanium aluminide by instrumented pulse electro-discharge consolidation of mechanically alloyed amorphous powder
}

\author{
H. KIMURA
}

Department of Mechanical Engineering, National Defense Academy, Hashirimizu 1-10-20, Yokosuka 239, Japan

A method of instrumented pulse electro-discharge consolidation combined with a technique of high rate heating of high quality mechanically alloyed amorphous TiAl powder is proposed, by which to obtain full densification via viscous flow and to control nano-scaled structure of titanium aluminide. For a pressure from 39 to $68 \mathrm{MPa}$, the present technique makes it possible to produce a full density compact of titanium aluminide within $170 \mathrm{~s}$ mainly in heating. The process viscosity ( $\eta$ ) as derived from the densification rate in real-time measurement is fairly well expressed by Arrhenius typed equation of $n=n o \exp (\mathrm{H} / \mathrm{kT})$, up to approximately $1300 \mathrm{~K}$, with an apparent activation energy $(\mathrm{H})$ of $2.1 \mathrm{eV}$, which is smaller than $3.5 \mathrm{eV}$ for material viscosity of amorphous TiAl. This indicates that rapidly full densification by high rate heating with $8.5 \mathrm{~K} \mathrm{~s}^{-1}$ occurs mostly via viscous flow in an amorphous TiAl phase(AM) with the aid of ion diffusion inferred from electro-discharging. Furthermore, a pulse electro-discharge consolidated compact is mainly found to consist of gamma TiAl and a high temperature $\alpha$-Ti phase around $1602 \mathrm{~K}$, and consequently have an increasing vickers hardness with increasing consolidating temperature, followed by a maximum of approximately 760 DPN. While compacts of gamma TiAl with $\alpha_{2}\left(\mathrm{Ti}_{3} \mathrm{Al}\right)$ produced at lower temperatures or by lower rate heating show a decreasing hardness. The obtained increase in hardness may be resulted from a nano-scaled structure and finely divided particle dispersion synthesized by a metastable reaction of $\mathrm{AM} \rightarrow \mathrm{TiAl}+\alpha-\mathrm{Ti}$ at a higher temperature.

\section{Introduction}

Intermetallic compounds, especially titanium aluminides, having a positive temperature dependence of yield strength is becoming one of the most promising candidate for a high-temperature material necessary to realize an aero-space plane. Powder metallurgy processing is a fruitful approach to material development from which to overcome less formability inherent in intermetallic compounds ${ }^{(1)}$.

Furthermore, the author has proposed two ways of non-equilibrium solid state powder processing combined with the mechanical alloying technique for the synthesis of intermetallic compounds, by which to obtain pore free consolidation and then to control an involved microstructure such as a nanoscaled phase ${ }^{(2)(3)}$. To date, the hot isostatic pressing(HIP) of mechanically alloyed amorphous TiAl powder makes it possible to produce a fully dense compact of amorphous TiAl below approximately $870 \mathrm{~K}$ according to HIP map based on viscous flow mechanism and then to synthesize nanoscaled structure of titanium aluminide via crystallization from an amorphous state ${ }^{(2)}$. Alternatively, instrumented pulse electro-discharge consolidation is developed by which to measure process parameters of temperature, pressure, current and displacement, so that amorphous TiAl powder can be consolidated in seconds, using a relatively low applied pressure, into a full density titanium 


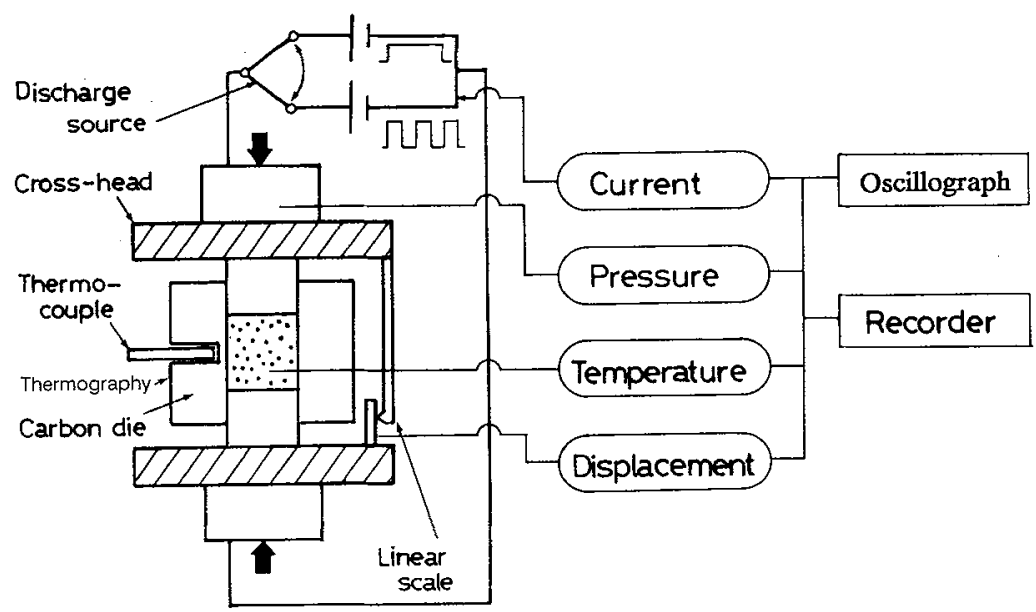

Figure 1. Instrumented pulse electro-discharge consolidation that has peripheral equipments to measure process parameters, temperature, pressure, electric current and displacement.

aluminide having an extremely high hardness of $1050 \mathrm{DPN}^{(3)}$.

The purpose of this article is to set up a way of instrumented pulse electro-discharge consolidation combined with a technique of high rate heating of high quality mechanically alloyed amorphous TiAl powder, in order to provide a route to material development of high-temperature titanium aluminides in wide-spread applications.

\section{Experimental Procedure}

Figure 1 illustrates the instrumented pulse electro-discharge consolidating apparatus(Sodic, Inc., PAS III) for the synthesis of a full density compact of high-temperature intermetallic compound using amorphous powder. This apparatus has peripheral equipments to measure temperature inside cabon die, pressure $(\sigma)$ applied to powder compact, current(I) and displacement. Figure 2 shows voltage waves of pulse-electric currents used in this machine, taken in terms of oscillograph.

Pulse electro-discharging consists of rectangular pulse(Mode I) and direct current superimposed alternating pulse with a steep rise(Mode II). Mode I can be used to excite outer layers of particles, and Mode II is useful to get the densification by volume flow under electro-discharging, especially by high rate heating. The temperatures $\left(\mathrm{T}_{e}, \mathrm{~T}_{\mathrm{c}}\right)$ at the edge and the center of the compact were

(a) Mode I

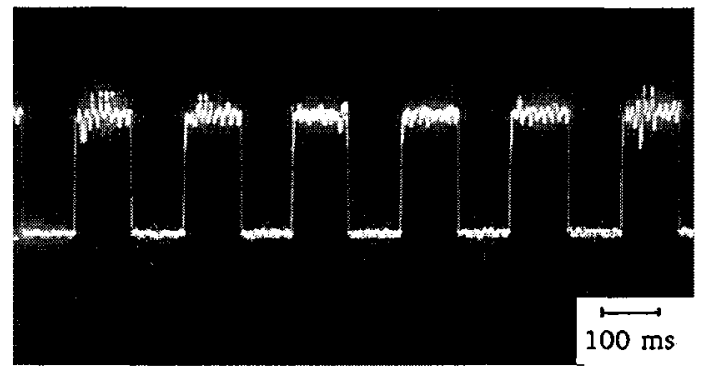

(b) Mode II

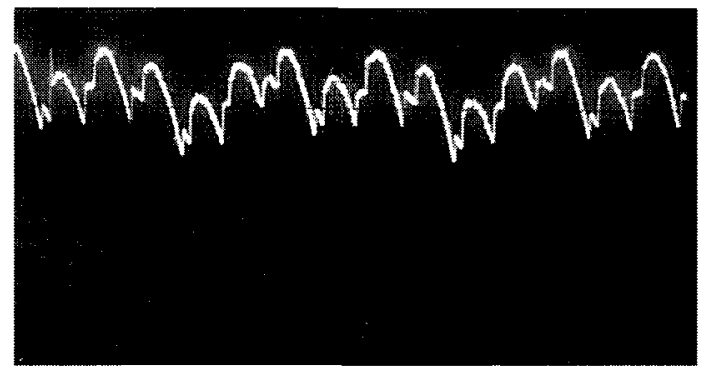

Figure 2. Voltage wave of pulse current, (a) Mode I;rectangular pulse(RP) with $I=800 \mathrm{~A},(\mathrm{~b})$ Mode $\mathrm{II}$; direct current superimposed alternating pulse(DC) with $\mathrm{I}=4000 \mathrm{~A}$. Zero level is denoted as + . 
estimated by correcting a temperature slope along the diameter of die. Mechanically alloyed amorphous TiAl powder having well-defined glass transition a sharp peak of ilcrystallization: and Fe-content less than $0.1 \%{ }^{(4)}$ is incorporated in carbon die with the outer diameter of $30 \mathrm{~mm}$ and the inner diameter of $10 \mathrm{~mm}$ and is electro-discharged in vacuum by Mode I. Then, powder compact was pressed using various pressure from 39 to $68 \mathrm{MPa}$ and heated up to a variety of the consolidating edge temperature between 1270 and $1743 \mathrm{~K}$ by Mode II.

The displacement(Z) of the powder compact were measured in real time during electrodischarging, followed by correction of thermal expansion of both punch. Here, the apparent relative density $\left(D_{a}\right)$ is defined by a relation of $D_{a}=H_{f} /\left(Z_{f}-Z+H_{f}\right)$ where $H_{f}$ and $Z_{f}$ are respectively the height of a full density compact and its displacement. The consolidated compact is characterized by $\mathrm{X}$ ray diffraction using $\mathrm{CuK} \alpha$. The vickers hardness of the compact is measured using a load of $1 \mathrm{kgf}$.

\section{Results}

\subsection{Instrumented pulse electro-discharge consolidation of amorphous TiAl powder}

Here, the densification process of mechanically alloyed amorphous TiAl powder which is consolidated by pulse electro-discharging into a full density compact is described, when using a heating rate of $\dot{\mathrm{a}}>8 \mathrm{~K} \mathrm{~s}^{-1}$. Figure 3 shows the temperature at the edge of compact and the apparent relative density vs. time using $\sigma=39 \mathrm{MPa}$ in the case of $\mathrm{T}_{\theta}=1602 \mathrm{~K}$. The apparent relative density shows a sharp increase, approaching to a nearly full density during heating by electro-discharging of Mode II with $\mathrm{I}=500$ and $1000 \mathrm{~A}$, following pulse electro-discharging of Mode I using $\mathrm{I}=750$ A. The total time necessary to obtain full densification is less than $170 \mathrm{~s}$. Figure 4 shows X-ray diffraction patterns of mechanically alloyed amorphous TiAl powder and the full density compact in the case of $T_{\theta}=1602 \mathrm{~K}$ for a holding time of $80 \mathrm{~s}$ as shown in Fig.3. This figure compares the pulse electro-discharge consolidated compact in the case of $T_{e}=1437 \mathrm{~K}$. The full density TiAl compact
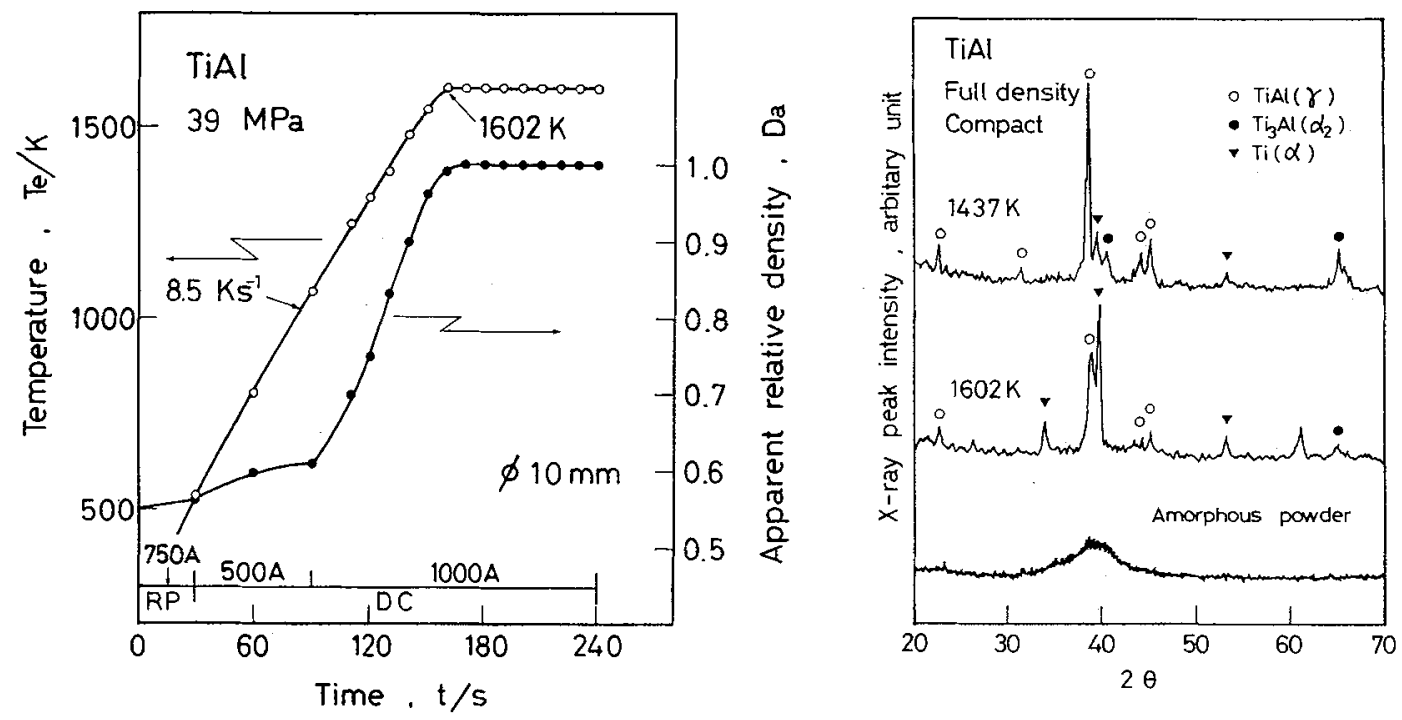

Figure 3. Temperature and apparent relative density vs. time using an applied pressure of $39 \mathrm{MPa}$ at the edge temperature of $1602 \mathrm{~K}$. Measurements taken during the pulse electro-discharge consolidation of mechanically alloyed amorphous TiAl powder.

Figure 4. X-ray diffraction pattern of the full density compact produced by the discharge consolidation of amorphous TiAl powder at $\mathrm{T}_{e}=1602 \mathrm{~K}$. This figure includes patterns of high quality mechanically alloyed amorphous TiAl powder and the compact, consolidated at $\mathrm{T}_{\mathrm{e}}=1437 \mathrm{~K}$. 
(a)

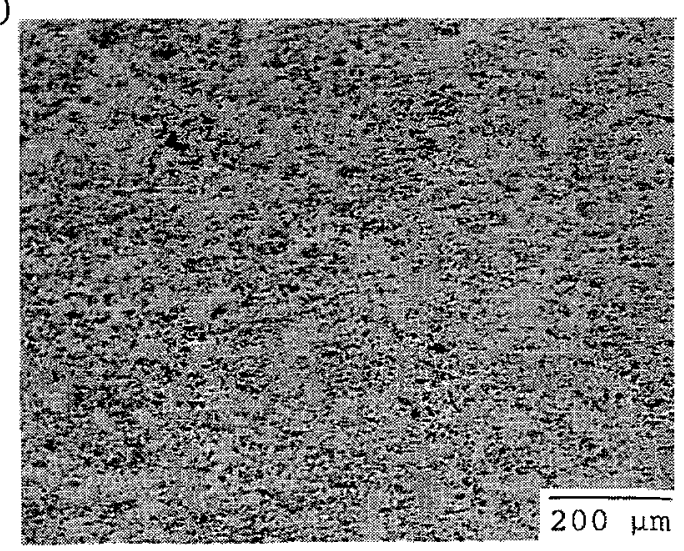

(b)

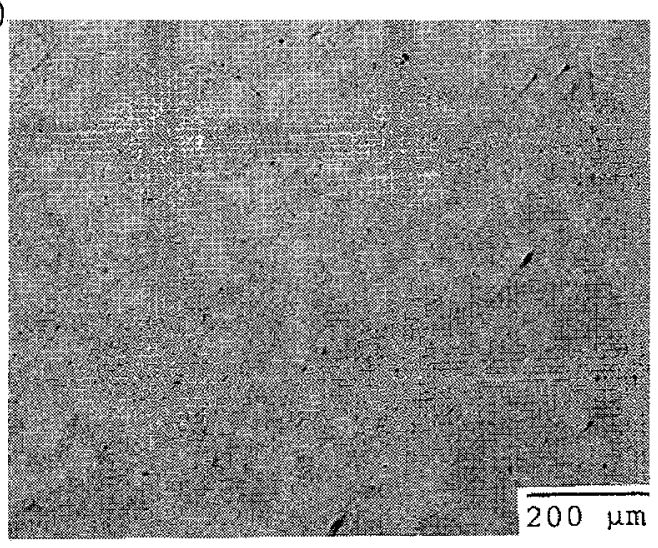

Figure 5. Optical micrograph of full density TiAl compacts, consolidated using pulse electrodischarging at the edge temperatures of (a) $T_{e}=1602 \mathrm{~K}$ and (b) $T_{e}=1437 \mathrm{~K}$.

at $T_{e}=1602 \mathrm{~K}$ consists of X-ray diffraction patterns identified as a high temperature phase, $\alpha$ TiAl and gamma TiAl. On the other hand, the full density compact which is consolidated at a lower temperature consists of gamma TiAl and $\alpha_{2}\left(\mathrm{Ti}_{3} \mathrm{Al}\right)$ with a small amount of $\alpha-\mathrm{Ti}$ in agreement with the compacts obtained by electro-discharge consolidation by a lower heating rate of $4.3 \mathrm{~K} \mathrm{~s}^{-1}$ using on-off controlled rectifying current. Note that the half width of gamma TiAl peak for the compact consolidated at $T_{e}=1602 \mathrm{~K}$ is a broader than that of the compact in the case of $T_{e}=1437 \mathrm{~K}$.

Figure 5 shows the surface structure of the full density TiAl compact, consolidated at (a) $T_{e}=1602$ $\mathrm{K}$ and $(\mathrm{b}) \mathrm{T}_{\mathrm{e}}=1437 \mathrm{~K}$ by optical microscopy. The precipitation of a great amount of $1 \mu \mathrm{m}$ sized $\alpha$-Ti can be seen in the gamma TiAl matrix in the case of $T_{e}=1602 \mathrm{~K}$, while island shaped particles of $\alpha_{2}$, and gamma TiAl with a small amount of $0.1 \mu \mathrm{m}$ sized $\alpha-\mathrm{Ti}^{\mathrm{i}}$ in the case of $\mathrm{T}_{\theta}=1437 \mathrm{~K}$. Furthermore, any microscopic discontinuity such as a microcrack, a pore at the triple point of particles and a boundary structure such as an oxide layer is not observed at the surface of both compacts. So, these pulse electro-discharge consolidated TiAl compacts are fully dense microscopically.

Figure 6 shows the density of the pulse electro-discharge consolidated TiAl compact vs. temperature using a variety of applied pressure from 39 to $68 \mathrm{MPa}$. The density of the full density TiAl compact is approximately $3.8 \mathrm{~g} \mathrm{~cm}^{-2}$; this value is nearly equal to $3.76 \mathrm{~g} \mathrm{~cm}^{-2}$ for gamma TiAl. For the compact obtained by high rate heating, the density shows a sharp increase up to the full density with increasing temperature. Then, the consolidating temperature necessary to obtain full densification increases with decreasing temperature, but this pressure dependence is smaller than that of full densification via superplastic flow of nanoscaled TiAl in the case of pulse electro-discharging by lower rate heating using rectified current ${ }^{(3)}$.

Figure 7 shows the vickers hardness vs. consolidating temperature for the full density compact of titanium aluminide produced by the pulse electro-discharging of high quality mechanically alloyed amorphous TiAl by relatively high rate heating with $\dot{a}=8.5 \mathrm{~K} \mathrm{~s}^{-1}$. This figure compares the full density TiAl compact obtained by pulse electro-discharge consolidation using on-off controlled rectifying current using $\dot{a}=4.3 \mathrm{~K} \mathrm{~s}^{-1}$. The pluse electo-discharge consolidated TiAl compact in the case of high rate heating is found to show an increase with increasing consolidating temperature and then following a maximum of $760 \mathrm{DPN}$ at $\mathrm{T}_{\mathrm{e}}=1602 \mathrm{~K}$, a decrease up to the melting point. While, the full density TiAl compact in the case of a lower rate heating with $\dot{\mathrm{a}}=4.3 \mathrm{~K} \mathrm{~s}^{-1}$ shows a monotonous decrease, following a peak of $1050 \mathrm{DPN}$ at approximately $1100 \mathrm{~K}^{(3)}$, with increasing consolidating temperature. The peak of the vickers hardness in the case of pulse electro-discharge consolidation with $\mathbf{a}=8.5$ $\mathrm{K} \mathrm{s}^{-1}$ appears in good agreement with the synthesis of gamma TiAl with the precipitation of the high temperature $\alpha$ phase as shown in Fig.5(a) 

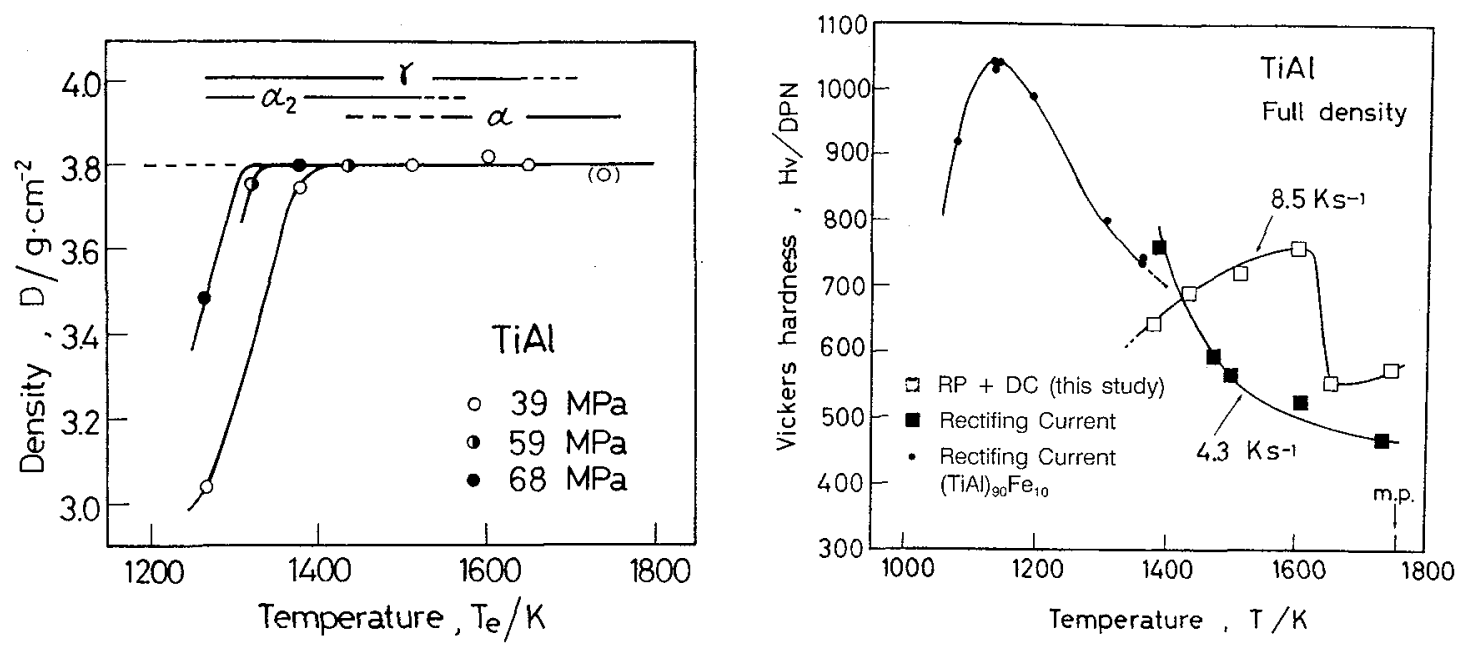

Figure 6. Density vs. consolidating temperature for pulse electro-discharge consolidated compacts of TiAl in the cases of applied pressure of 39,59 and $68 \mathrm{MPa}$.

Figure 7. Vickers hardness vs. consolidating temperature for full density TiAl compacts consolidated by higher rate heating $\left(8.5 \mathrm{~K} \mathrm{~s}^{-1}\right)$, comparing with those of lower rate heating or lower temperatures.

\section{Discussion}

Consider process parameters and a densification mechanism for pulse electro-discharge consolidation by the high rate heating of mechanically alloyed amorphous TiAl powder. The sintering strain rate $(\dot{E})$ is defined with the relative density (D) as follows,

$$
\dot{\varepsilon}=(1 / \mathrm{D})(\mathrm{dD} / \mathrm{dt})
$$

Figure 8 shows the apparent relative density as a function of consolidating temperature at the edge of the powder compact of amorphous TiAl in the case of $39 \mathrm{MPa}$, obtained from Figure 3 . When the electro-discharging of Mode II is applied, the apparent relative density shows a small linear increase up to $T_{v}$ where the shrinkage via plastic flow start, and then a drastic increase via viscous flow. The discharging of Mode I do not contribute the densification. The linear increase consists of thermal shrinkage compensating thermal expansion of powder compact and so is recognized as a base line for the estimation of the increase in relative density $\left(D_{v}\right)$ by plastic flow. Then, the densification rate $\left(D_{v} / d t\right)$ via plastic flow is derived from a relation of $\left(\mathrm{dD}_{\mathrm{v}} / \mathrm{dT}\right)(\mathrm{dT} / \mathrm{dt})$.

The process viscosity during electro-discharge consolidation is expressed by a following equation:

$$
n=\sigma_{\text {eff }} / 3 \dot{\varepsilon}
$$

where $\sigma_{\text {eff }}$ is the effective stress applied to a contacted area between particles. The equation of $\sigma_{\text {eff }}=\sigma\left(1-D_{0}\right) / D{ }^{2}\left(D-D_{0}\right)$ for a lower density compact under isostatic pressing with $0.64<D<0.9$ is applicable to the pulse electro-discharge consolidating compact in plane strain state where quasihydrostatic pressure presents. Figure 9 shows thus-obtained process viscosity for the powder TiAl compact during pulse electro-discharging as a function of reciprocal temperature. The process viscosity is fairly well expressed by Arrhenius typed equation as follows,

$$
\eta=n_{0} \exp (\mathrm{H} / \mathrm{kT})
$$

where $\mathrm{H}$ is an apparent activation energy for the densification via viscous flow under pulse electrodischarging. The activation energy for electo-discharge consolidation of amorphous TiAl is derived at $2.6 \mathrm{eV}$, this value is smaller than $3.5 \mathrm{eV}$ for the material viscosity which is measured by a thermomechanical analyzer without discharging ${ }^{(5)}$. This finding indicates that full densification by high 

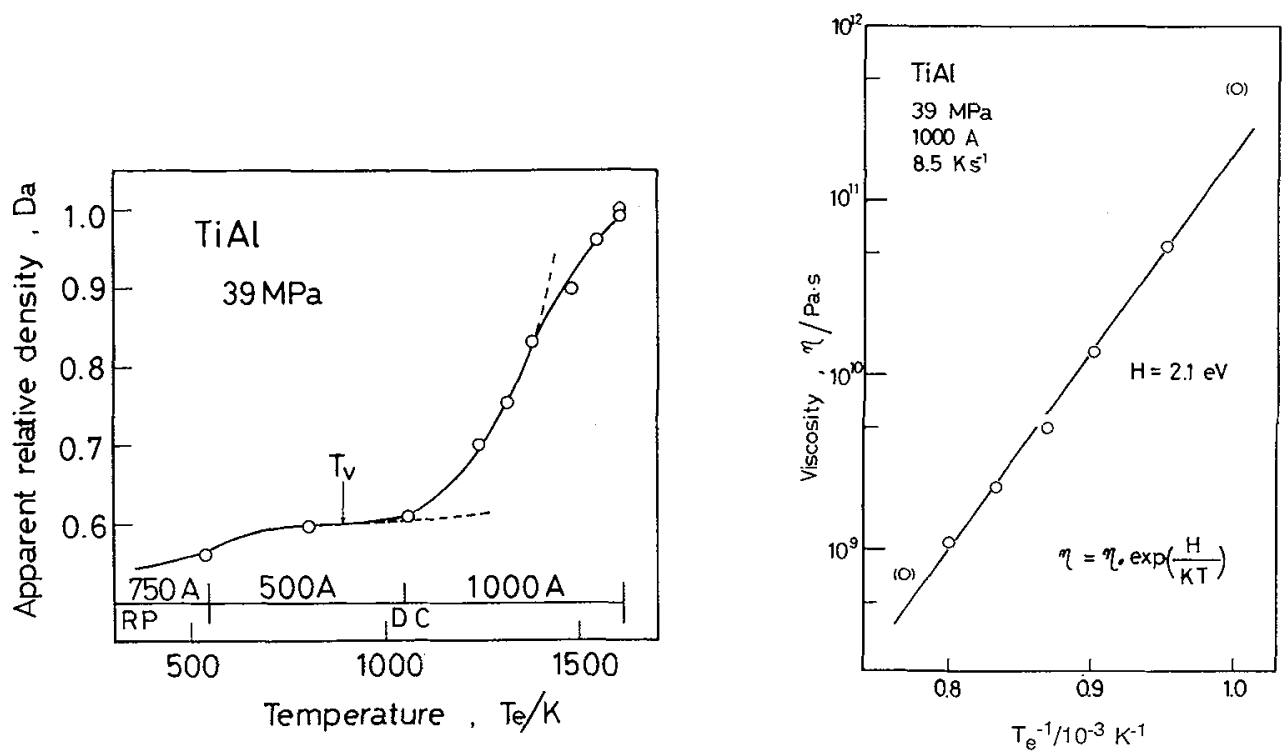

Figure 8. Apparent relative density as a function of temperature for the powder compact of high quality mechanically alloyed amorphous TiAl during pulse electro-discharging.

Figure 9. Process viscosity vs. reciprocal temperature for amorphous TiAl compact under discharging.

rate heating occurs via a thermally activated process of viscous flow with the aid of ion diffusion inferred from electo-discharging. On the other hand, the deviation from the linearity of equation(3) is ascribed to the onset of crystallization of an amorphous TiAl phase(AM) at relatively high temperature of approximately $1300 \mathrm{~K}$. So, the high rate heating makes it possible to present a high temperature nonequibrium transformation of $\mathrm{AM}-$ gamma TiAl $+\alpha$-Ti. The peak in hardness may be resulted from increasing volume fraction of $\alpha$-Ti with increasing temperature and nano-scaled structure of gamma TiAl. When further high rate heating avoiding the transformation of $\mathrm{AM} \rightarrow \mathrm{gamma} \mathrm{TiAl}+\alpha_{2}$ is applicable, the temperature at the peak of the hardness shifts to $T_{e}=1437 \mathrm{~K}$.

\section{Conclusion}

Pulse electro-discharge consolidation combined with a high rate heating technique has been proposed to develop the high-temperature nanoscaled titanium aluminide using mechanically alloyed amorphous TiAl powder. The proposed technique would permit to obtain rapidly full densification via viscous flow of amorphous TiAl mostly in heating. The consequent metastable reaction of $\mathrm{AM} \rightarrow$ gamma $\mathrm{TiAl}+\mathrm{alpha} \mathrm{Ti}$ around $1602 \mathrm{~K}$ leads to an increase in hardness, following a maximum of $760 \mathrm{~K}$ at $1602 \mathrm{~K}$ with increasing temperature. This increase may be resulted from nanoscaled structure and particle dispersion synthesized in the high-temperature crystallization.

\section{References}

(1) For example, Intermetallic Compounds -structure and mechanical properties-, Ed. by O. Izumi(JIMIS6, Sendai Japan, 1991 June), Japan Institute of Metals.

(2) H. Kimura and S. Kobayashi, p.985 in ref(1).

(3) H. Kimura and S. Kobayashi, J. Japan Institute of Metals in the press.

(4) H. Kimura, S. Kobayashi, S. Sugawara and E. Fukazawa, J. Japan Society of Powder and Powder Metallurgy, 40(1993)278.

(5) S. Kobayashi, Master thesis of National Defense Academy(1992). 